\title{
Restbestand $\mathrm{ICH}$
}

\section{Bernhard Gurtner}

«Ich habe immer ausgezeichnete Zähne gehabt, und erst jetzt fängt das Alter an, sie zu bedrohen. Gott begnadet die, denen er das Leben nach und nach verlöschen lässt; der endgültige Tod wird dadurch weniger vollständig und weniger furchtbar; er hat es nur noch mit einem halben Menschen zu tun.

Jetzt ist mir also ein Zahn ausgefallen, schmerzlos, von selbst; es war dies das natürliche Ende seiner Zeit: nun ist dieser Teil meines Wesens schon tot; andere Teile von mir sind halb tot, und zwar besonders jene Teile, die während der Blütezeit meiner Jugend die erste Rolle spielten. So schmelze ich allmählich dahin und entziehe mich nach und nach meinem Selbst. Wie dumm müsste ich sein, wenn ich den Sprung von diesem Niedergang aus, der schon so weit fortgeschritten ist, als ebenso tief empfände, wie wenn es der ganze Sprung wäre!»

Michel de Montaigne 1533-1592

Wie viel darf man von einem Menschen wegnehmen herausoperieren - amputieren? Er verliert doch im wahrsten Sinne des Wortes seine Individualität, er ist teilbar geworden. Was bleibt, ist jedesmal ein etwas kleiner gewordener Restposten vom eigenen ICH.

«Man kommt sich selbst abhanden.»

Max Frisch, nach einem Zahnverlust

Hat man Ihnen schon den Blinddarm entfernt, die Appendix, genauer gesprochen? Haben Sie so eine kleine Narbe am rechten Unterbauch? Ja? Fühlen Sie sich seither als minderwertiger Mensch? Ohne Wurmfortsatz? Gewiss nicht. Und ohne Gallenblase? Nicht unbedingt? Mit verkleinertem Magen und bloss einer Niere? Schon eher? Ab wann ist man nur noch eine halbe Portion? Warum möchten Hemiplegiker im Schlaf ihr gelähmtes Bein aus dem Bett werfen? Gehört es nicht mehr zu ihrem Selbst?

Korrespondenz: Dr.med. Bernhard Gurtner Eggstrasse 6 CH-8620 Wetzikon gurtner.bernhard[at] bluewin.ch bewusstsein? Auf was können Männer keinesfalls verzichten?

Alle Körperzellen werden angeblich innerhalb von sieben Jahren erneuert; Zweifel sind angebracht, wenn man die vielen Glatz- oder Dummköpfe in Betracht zieht, deren Haare und Hirnzellen sich nicht an diese Regel halten. Hingegen werden Billionen Blutkörperchen und die Epithelien der Hohlorgane in viel kürzeren Abständen durch neue Zellen ersetzt. Wird dabei auch das ICH immer wieder umgebaut? Was geht mit unserem Atem, Schweiss, Urin und Stuhl an eigener Substanz verloren? Wir bestehen ja nur aus geliehenen Molekülen, aus LEGO-Teilchen, die auf unserem Planeten seit Urzeiten beliebig und zufällig zwischen Luft und Wasser, Gesteinen, Pflanzen und Tieren austauschbar sind. Wem gehören die Spurenelemente, die wir in unserem Körper als unentbehrlichen Schatz hüten und doch immer wieder verlieren?

Wann geht mit zunehmender Demenz das ICH unwiderruflich verloren? Verbleiben einige Inseln im Meer des Vergessens, wenn geistig Aussätzige als schutzwürdige Gruppe liebevoll betreut werden? Bis wann und für wen lohnt sich der grosse Pflegeaufwand? Für die Dementen selbst oder schlussendlich nur noch für deren Umfeld? Wie fühlt man sich mit all den eingebauten Ersatzteilen: mit Zahnimplantaten, leichtgängigen Gelenken aus Edelstahl, mit Stents in wieder durchgängig gemachten Blutgefässen, mit fensterklaren Augenlinsen nach Staroperation? Was empfindet man - und frau - mit transplantierten Organen? Was bedeutet das heftige Klopfen eines gespendeten Herzens? Wird die Tachykardie nur durch Katecholamine des Empfängers angetrieben oder zeigt sich so noch posthum die einstige Reizbarkeit des Verstorbenen?

Der moderne Mensch wird körperlich immer wieder renoviert und oft mit Pharmaka psychisch adaptiert. Wie heisst die mir fremd gewordene Person, die jeden Morgen im Spiegel des Badezimmers behauptet, ICH zu sein? Sie blinzelt mir mit dem rechten Auge zu, wenn ich das linke zukneife, zieht aber beide Mundwinkel hoch, wenn mir - dank Zahnimplantaten - zu Tagesbeginn ein Lächeln gelingt. :-) 